\title{
Severe hypertension in pregnancy
}

\author{
Authors: Kate Wiles, ${ }^{A}$ Mellisa Damodaram ${ }^{B}$ and Charlotte Frise ${ }^{C}$
}

Severe hypertension in pregnancy is defined as a sustained systolic blood pressure of $160 \mathrm{mmHg}$ or over or diastolic blood pressure of $110 \mathrm{mmHg}$ or over and should be assessed in hospital. Severe hypertension before 20 weeks' gestation is rare and usually due to chronic hypertension; assessment for target organ damage and exclusion of secondary hypertension are warranted. The most common cause of severe hypertension in pregnancy is pre-eclampsia, which presents after 20 weeks' gestation. This warrants more rapid control of blood pressure due to the risk of haemorrhagic stroke, and intravenous antihypertensive agents may be required. Treatment is determined by licensing, availability and clinician experience, with no high-level evidence to guide prescribing. Labetalol is the agent most commonly used, both orally and intravenously, in pregnancy in the UK. Severe hypertension is a risk factor for sustained hypertension after pregnancy. Hypertension in pregnancy is associated with increased cardiovascular risk.

\section{Definitions}

There is international consensus that a normal blood pressure in pregnancy is less than $140 \mathrm{mmHg}$ systolic and $90 \mathrm{mmHg}$ diastolic. This definition was originally derived from non-pregnant populations, with later assessment of the normal distribution of blood pressure values in pregnancy. More recent prospective cohort data have shown that the reference limit (97th percentile) for blood pressure has a nadir of $138 / 86 \mathrm{mmHg}$ at gestational weeks $18-20$, rising to $144 / 95 \mathrm{mmHg}$ at term. When these data are restricted to women aged under 40 years, with body mass index less than $30 \mathrm{~kg} / \mathrm{m}^{2}$ and an absence of underlying conditions and pregnancy complications, the nadir is $132 / 83 \mathrm{mmHg}$, rising to $138 / 90 \mathrm{mmHg}$ at 38 weeks' and $140 / 92 \mathrm{mmHg}$ at 40 weeks' gestation. ${ }^{1}$ These data support the long-standing threshold of $140 / 90 \mathrm{mmHg}$ for the diagnosis of hypertension in pregnancy.

Severe hypertension in pregnancy is defined as a sustained systolic blood pressure of $160 \mathrm{mmHg}$ or over, or diastolic blood pressure of $110 \mathrm{mmHg}$ or over. This definition is also derived from long-standing consensus, supported by case series of maternal

Authors: ${ }^{\text {A }}$ consultant obstetric physician, The Royal London Hospital, London, UK; ${ }^{B}$ subspecialty trainee in maternal and fetal medicine, Queen Charlotte's and Chelsea Hospital, London, UK; ${ }^{C}$ consultant obstetric physician, Oxford University Hospitals NHS Foundation Trust, Oxford, UK and Queen Charlotte's and Chelsea Hospital, London, UK haemorrhagic stroke and aortic dissection in pregnant women with systolic blood pressures greater than $160 \mathrm{mmHg}$.,3

\section{Aetiology}

Hypertension affects up to $10 \%$ of pregnant women and is due to either pre-existing chronic hypertension or a new pregnancyinduced hypertensive disorder. Timing of disease may distinguish chronic hypertension from gestational hypertension, as chronic hypertension presents prior to 20 weeks' gestation and persists after pregnancy. Endothelial dysfunction distinguishes preeclampsia from other pregnancy-induced hypertensive disorders and includes one or more of:

> proteinuria: new urinary protein:creatinine ratio over $30 \mathrm{mg} / \mathrm{mmol}$

> acute kidney injury: new serum creatinine over $90 \mu \mathrm{mol} / \mathrm{L}$

> liver involvement: alanine aminotransferase over $40 \mathrm{IU}$, right upper quadrant or epigastric pain

> haematological complications: thrombocytopenia less than $150 \times 10^{9} / \mathrm{L}$ or haemolysis

\section{Key points}

Severe hypertension in pregnancy is defined as a sustained systolic blood pressure of $160 \mathrm{mmHg}$ or over or diastolic blood pressure of $110 \mathrm{mmHg}$ or over.

The most common cause of severe hypertension in pregnancy is pre-eclampsia, which presents after 20 weeks' gestation.

Severe hypertension before 20 weeks' gestation is usually due to chronic hypertension, and requires assessment for target organ damage and exclusion of secondary causes of hypertension.

Oral and intravenous labetalol and oral modified-release nifedipine are used for the control of severe hypertension in women with pre-eclampsia.

Chronic hypertension and pre-eclampsia are vascular risk factors, therefore postnatal counselling is advocated, with management of modifiable risk.

KEYWORDS: pregnancy, hypertension, pre-eclampsia

DOI: 10.7861/clinmed.2021-0508 


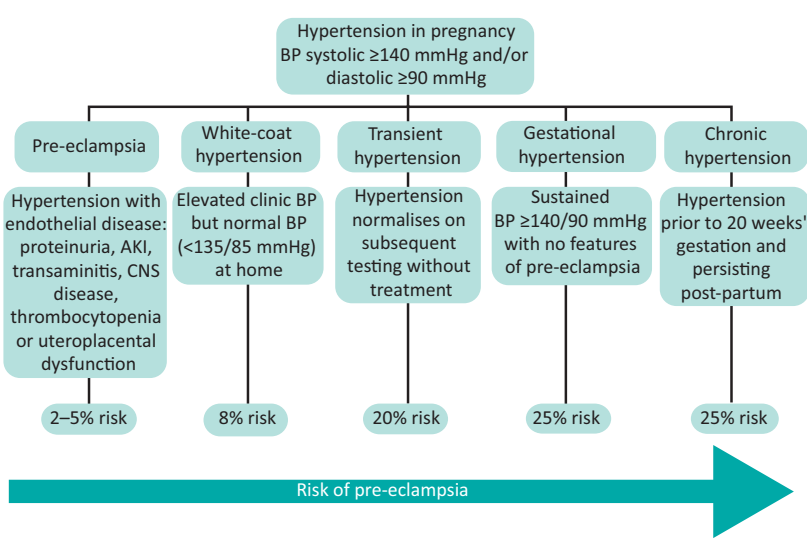

Fig 1. Hypertensive disorders in pregnancy. AKI = acute kidney injury; $\mathrm{BP}=$ blood pressure; $\mathrm{CKD}=$ chronic kidney disease; $\mathrm{CNS}=$ central nervous system; CVD = cardiovascular disease.

> cerebral symptoms or signs in the absence of another cause: headache, visual scotomata or clonus

> uteroplacental insufficiency: fetal growth restriction, abnorma umbilical artery Doppler. ${ }^{4}$

Even transient and white-coat hypertension are not benign disorders in pregnancy, conferring a risk of progression to gestational hypertension and pre-eclampsia. Disease definitions are shown in Fig 1.5

\section{Severe hypertension before 20 weeks' gestation: chronic hypertension}

Chronic hypertension affects $8 \%$ of women of childbearing age and $3 \%$ of pregnancies. In the absence of routine blood pressure checks outside pregnancy, chronic hypertension may be diagnosed for the first time during pregnancy as a sustained blood pressure $\geq 140 / 90 \mathrm{mmHg}$ prior to 20 weeks' gestation. Chronic hypertension can, however, be masked by the physiological changes of pregnancy, which include systemic and renal vasodilatation and a decrease in systemic vascular resistance. Chronic hypertension can therefore also manifest as persistent hypertension beyond the postpartum period.

Severe hypertension prior to 20 weeks' gestation is most commonly asymptomatic, and accelerated hypertension is unlikely in the context of gestational physiology. However, all women with severe hypertension should be assessed in a hospital setting. Appropriate clinical care pathways should be agreed for women presenting with hypertension prior to 20 weeks' gestation. In the UK, specialty referral is commonly determined by gestation, with referral to general medicine prior to 18-20 weeks and referral to obstetric services only at later gestations. This may not be appropriate for women with hypertension in early pregnancy, who should benefit from the expertise that obstetricians and obstetric physicians have in the pregnancy-specific management of hypertension, as well as established pathways for outpatient management and surveillance.

Due to the physiological changes of pregnancy, severe hypertension prior to 20 weeks' gestation is rare. Where severe hypertension does occur before 20 weeks' gestation, the possibility of secondary hypertension should be considered, particularly in the absence of a family history of hypertension and whenever there is treatment resistance (Table 1). ${ }^{6}$ Assessment for possible target organ damage is also required (Table 2$)^{6}$

Treatment with hypertensive agents should be initiated, aiming for an initial target blood pressure below $160 / 110 \mathrm{mmHg}$, and an eventual target $110-135 / 70-85 \mathrm{mmHg}$ for the remainder of the pregnancy. ${ }^{7}$ In the absence of accelerated hypertension and pre-eclampsia, severe hypertension in pregnancy can usually be treated with oral agents (see Table 3), with blood pressure control achieved over days, rather than hours. A sufficient response to oral treatment should, however, be confirmed with close clinical surveillance whenever outpatient management of hypertension in pregnancy is undertaken. Inpatient assessment and management of severe hypertension in the absence of pre-eclampsia is warranted for women with symptoms, atypical features, retinopathy, abnormal cardiovascular or neurological findings, acute kidney injury or if there is any other clinical concern.

\section{Severe hypertension after 20 weeks' gestation}

Severe hypertension after 20 weeks' gestation can occur due to gestational hypertension, pre-eclampsia, superimposed gestational hypertension/pre-eclampsia in women with chronic hypertension, or poor control of chronic hypertension (see Fig 1). Most severe hypertension in pregnancy occurs in the context of pre-eclampsia. However, clinicians should not be reassured by the absence of clinical features of pre-eclampsia (usually proteinuria), as severe hypertension is associated with an increased risk of adverse maternal and fetal outcomes even in the absence of pre-eclampsia (Table 4). ${ }^{8-11}$

\section{Management of severe hypertension in pregnancy}

Historically, strict blood pressure control in pregnancy was avoided due to theoretical concern that treatment compromised the fetal circulation and contributed to adverse neonatal outcomes. A randomised controlled trial of 'tight' (target diastolic $85 \mathrm{mmHg}$ ) with 'less tight' (100 mm Hg) blood pressure control in pregnancy was designed to address this. Although achieved blood pressure difference between groups was lower than intended (139/90 $\mathrm{mmHg}$ versus $133 / 85 \mathrm{mmHg}$ ), tighter control was associated with a reduction in the incidence of severe hypertension $(28 \%$ versus $41 \%$ ) and its associated adverse outcomes (Table 4). ${ }^{12}$ A systematic review including 59 trials and 4,723 pregnant women with blood pressures between 140-169 / 90-109 mmHg demonstrated that antihypertensive treatment halved the risk of severe maternal hypertension, with no adverse effects on fetal outcomes. ${ }^{13}$ Evidence of a reduction in severe maternal hypertension, in the absence of adverse fetal and neonatal consequences, has been sufficient to reduce the threshold at which antihypertensive treatment is commenced in pregnancy in the UK from $150 / 100 \mathrm{mmHg}$ to $140 / 90 \mathrm{mmHg}^{14}$

The choice of antihypertensive agent in pregnancy is determined by licensing, availability and clinician experience, with no high-level evidence to guide prescribing. ${ }^{14}$ Labetalol, modified-release nifedipine and methyldopa are considered safe for use in pregnancy and are the most commonly used drugs in the UK. Fewer safety data are available for amlodipine and doxazosin, although no adverse fetal effects are reported. ${ }^{15}$ Angiotensin-converting enzyme inhibitors (ACEi) and angiotensin receptor antagonists are contraindicated due to fetotoxicity in the second and third trimesters. Enalapril is, however, 
Table 1. Secondary causes of hypertension in pregnancy

\begin{tabular}{|c|c|c|}
\hline Aetiology & $\begin{array}{l}\text { Clinical assessment in } \\
\text { pregnancy }\end{array}$ & Diagnosis and management in pregnancy \\
\hline Coarctation & $\begin{array}{l}\text { Upper limb hypertension } \\
\text { Radio-/brachiofemoral delay } \\
\text { Systolic murmur from associated } \\
\text { bicuspid aortic valve } \\
\text { Turner's syndrome phenotype }\end{array}$ & Echo/MRI \\
\hline Chronic kidney disease & $\begin{array}{l}\text { Symptoms: oedema, arthralgia, } \\
\text { rash, hair loss, visible haematuria, } \\
\text { recurrent UTI and family history } \\
\text { Renal bruit } \\
\text { Urine dip } \\
\text { Quantification of proteinuria } \\
\text { Serum creatinine } \\
\text { Kidney ultrasound for morphology } \\
\text { and symmetry }\end{array}$ & $\begin{array}{l}>2+\text { blood or protein on urine dip warrants further assessment } \\
\text { UACR }>8 \mathrm{mg} / \mathrm{mmol} \text { and } \mathrm{uPCR}>30 \mathrm{mg} / \mathrm{mmol} \text { are abnormal in pregnancy } \\
\text { Creatinine }>77 \mu \mathrm{mol} / \mathrm{L} \text { is abnormal in pregnancy } \\
\text { Imaging of renal vasculature usually delayed until postpartum, provided } \\
\text { safe blood pressure control can be achieved } \\
\text { ACEi and ARB contraindicated due to fetotoxicity }\end{array}$ \\
\hline $\begin{array}{l}\text { Hyperaldosteronism / } \\
\text { Conn's syndrome }\end{array}$ & $\begin{array}{l}\text { Hypokalaemia } \\
\text { Treatment resistance }\end{array}$ & $\begin{array}{l}\text { Gestational increases in renin and aldosterone prevent accurate } \\
\text { interpretation } \\
\text { Formal diagnosis usually delayed until postpartum, provided safe blood } \\
\text { pressure control can be achieved } \\
\text { Spironolactone contraindicated due to anti-androgenic fetal effects } \\
\text { Limited data on the use of amiloride and eplerenone in pregnancy }\end{array}$ \\
\hline Cushing's syndrome & $\begin{array}{l}\text { Phenotype: thin skin, bruising, } \\
\text { striae, fat distribution, proximal } \\
\text { weakness, elevated plasma } \\
\text { glucose/early diagnosis of GDM }\end{array}$ & $\begin{array}{l}\text { Phenotype overlaps with normal pregnancy } \\
\text { Gestational increase in cortisol prevents accurate interpretation } \\
\text { Formal diagnosis usually delayed until postpartum, provided safe blood } \\
\text { pressure control can be achieved }\end{array}$ \\
\hline $\begin{array}{l}\text { Phaeochromocytoma/ } \\
\text { paraganglioma }\end{array}$ & $\begin{array}{l}\text { Headache, sweating, tachycardia, } \\
\text { anxiety } \\
\text { Episodic hypertension }\end{array}$ & $\begin{array}{l}\text { Urine and plasma metanephrine concentrations unaffected by pregnancy. } \\
\text { Non-contrast MRI } \\
\text { MIBG contraindicated due to placental transfer; maternal benefit of alpha- } \\
\text { blockade outweighs risk; labetalol has insufficient alpha-blockade in isolation }\end{array}$ \\
\hline Hyperparathyroidism & $\begin{array}{l}\text { Nausea/hyperemesis, constipation, } \\
\text { low mood, polyuria } \\
\text { Serum calcium and PTH }\end{array}$ & $\begin{array}{l}\text { Significant maternal (pancreatitis, kidney injury, nephrolithiasis, pre- } \\
\text { eclampsia) and fetal (miscarriage, intrauterine death) risks warrant early } \\
\text { diagnosis and support definitive surgical treatment in pregnancy }\end{array}$ \\
\hline
\end{tabular}

Table 2. Target organ damage due to chronic hypertension

\begin{tabular}{|c|c|c|c|}
\hline Organ & Pathology & Assessment & Considerations in pregnancy \\
\hline Heart & $\begin{array}{l}\text { Left ventricular hypertrophy/ } \\
\text { remodelling } \\
\text { Impaired cardiac function } \\
\text { Ischaemic heart disease }\end{array}$ & $\begin{array}{l}\text { Clinical examination } \\
\text { ECG } \\
\text { Echo }\end{array}$ & $\begin{array}{l}30-50 \% \text { increase in cardiac output required for pregnancy } \\
\text { Cardiac disease is commonest cause of maternal death in UK }\end{array}$ \\
\hline Kidneys & $\begin{array}{l}\text { Albuminuria } \\
\text { Proteinuria } \\
\text { Hypertensive nephropathy } \\
\text { Chronic kidney disease }\end{array}$ & $\begin{array}{l}\text { UACR/UPCR } \\
\text { Serum creatinine }\end{array}$ & $\begin{array}{l}\text { UACR }>8 \mathrm{mg} / \mathrm{mmol}, \mathrm{UPCR}>30 \mathrm{mg} / \mathrm{mmol} \text { and serum creatinine } \\
>77 \mu \mathrm{mol} / \mathrm{L} \text { are abnormal in pregnancy } \\
\text { CKD confers risk of adverse pregnancy outcome and loss of } \\
\text { maternal kidney function }\end{array}$ \\
\hline $\begin{array}{l}\text { Retina and } \\
\text { brain }\end{array}$ & $\begin{array}{l}\text { Hypertensive retinopathy } \\
\text { Hypertensive/ischaemic optic } \\
\text { neuropathy }\end{array}$ & Fundoscopy & $\begin{array}{l}\text { Consider hypertensive crisis, warrants inpatient assessment/ } \\
\text { management } \\
\text { Needs exclusion of secondary hypertension }\end{array}$ \\
\hline Arteries & $\begin{array}{l}\text { Increased peripheral arterial } \\
\text { stiffness } \\
\text { Atherosclerosis }\end{array}$ & & $\begin{array}{l}\text { Consider vascular risk in pregnancy } \\
\text { Serum cholesterol increases in pregnancy and is not routinely } \\
\text { checked or treated }\end{array}$ \\
\hline
\end{tabular}

$\mathrm{CKD}$ = chronic kidney disease; ECG = electrocardiography; Echo = echocardiography; $\mathrm{UACR}=$ urinary albumin:creatinine ratio, uPCR = urinary protein:creatinine ratio. 
Table 3. Antihypertensive treatment in pregnancy

\section{Typical dose}

\section{Oral medications}

Labetalol

100-800 mg TDS

Modified-release

nifedipine

$10-40 \mathrm{mg} \mathrm{BD}$

nifedipine

Amlodipine

5-10 mg OD

Methyldopa

$250 \mathrm{mg}-1 \mathrm{~g}$ TDS

2-16 mg total daily dose

Doxazosin

Prazosin

0.5-6 mg BD-TDS

\section{Intravenous medications}

Labetalol

$\begin{array}{ll}\text { Hydralazine } & \text { Bolus: } 5 \text { mg over } 10 \\ & \text { minutes can be repeated } \\ & \text { in 20-30 minutes. Follow } \\ & \text { with infusion if required } \\ & \text { Infusion: } 5 \mathrm{mg} / \mathrm{hour}, \\ & \text { titrated to blood pressure }\end{array}$

\section{Postpartum}

Enalapril

2.5-10 mg BD orally

\section{Cautions}

Asthma

Decompensated heart

failure

Immediate-release and sublingual preparations are not used in UK due to unpredictable hypotensive effect

Previous intolerance

Liver dysfunction

Mood disorder

Postural hypotension

Postural hypotension

Asthma

Decompensated heart

failure

Maternal tachycardia

(heart rate $>120 \mathrm{bpm}$ )

Contraindicated in pregnancy

Hyperkalaemia

Acute kidney injury
Peak onset

2-4 hours

First line in UK as licensed for pregnancy

Monitor for neonatal hypoglycaemia

$1.5-4.2$ hours

Most common second-line treatment

Racial differences in blood pressure response to calcium channel blockers have not been investigated in pregnancy

6-8 hours Limited data for pregnancy but no evidence of harm

6-9 hours

2-3 hours

Not used postpartum due to exacerbation of depression

Limited data but no evidence of harm

Accumulation in milk in animal studies not replicated in limited human data

30-90 minutes

Limited data but no evidence of harm in pregnancy and lactation

5-10 minutes Needs invasive BP monitoring Consider other aspects of care for pre-eclampsia with severe features:

Intravenous magnesium Fluid balance/restriction Fetal wellbeing Plans for delivery

15-30 minutes

Needs invasive BP monitoring Reduction in blood pressure less predictable than with labetalol Careful fluid balance: caution with plasma expansion due to the risk of pulmonary oedema in pre-eclampsia

4-6 hours

Fetotoxic in 2nd and 3rd trimester Used for postpartum hypertension including lactation Hypothesised benefit in regression of proteinuria and cardiac remodelling after preeclampsia

$\mathrm{BD}=$ twice daily; $\mathrm{BP}=$ blood pressure; $\mathrm{bpm}=$ beats per minute; $\mathrm{OD}=$ once daily; $\mathrm{TDS}=$ three times daily. 
Table 4. Pregnancy outcomes and risk in severe hypertension compared with pre-eclampsia in the absence of severe hypertension

\begin{tabular}{|c|c|c|c|c|}
\hline & $\begin{array}{l}\text { Gestational } \\
\text { hypertension, } \\
\%^{8,9}\end{array}$ & $\begin{array}{l}\text { Preeclampsia without } \\
\text { severe features, BP } \\
<160 / 110 \mathrm{mmHg} \%{ }^{8,9}\end{array}$ & $\begin{array}{l}\text { Severe gestational } \\
\text { hypertension, BP } \\
\geq 160 / 110 \mathrm{mmHg}, \% \text {,9 }\end{array}$ & $\begin{array}{l}\text { Odds ratio }(95 \% \mathrm{CI}) \text { for outcome } \\
\text { in severe hypertension adjusted } \\
\text { for pre-eclampsia }\end{array}$ \\
\hline \multicolumn{5}{|l|}{ Maternal outcomes } \\
\hline Elevated liver enzymes & 1.1 & 3.2 & 6.3 & $2.47(1.12-5.43)$ \\
\hline Placental abruption & $0.3-1.3$ & $0.5-3.2$ & $3.1-4.2$ & \\
\hline DIC & 0.1 & 0.5 & 3.1 & \\
\hline Induction of labour & 23.8 & 41.5 & 50 & \\
\hline Caesarean delivery & 29.1 & 30.9 & 28.1 & \\
\hline \multicolumn{5}{|l|}{ Neonatal outcomes } \\
\hline $\begin{array}{l}\text { Delivery }<37 \text { weeks' } \\
\text { gestation }\end{array}$ & 17.8 & 25.8 & 54.2 & $2.59(1.83-3.68)$ \\
\hline $\begin{array}{l}\text { Delivery }<34 \text { weeks' } \\
\text { gestation }\end{array}$ & 1 & 1.9 & 3.2 & $3.07(1.97-4.80)$ \\
\hline Small for gestational age & $6.5-6.9$ & $4.8-9.2$ & $10.2-20.8$ & $1.75(1.19-2.58)$ \\
\hline Birthweight $<2,500 \mathrm{~g}$ & 7.7 & 11.1 & 25.8 & \\
\hline $\begin{array}{l}\text { Intensive care unit } \\
\text { admission }\end{array}$ & $12.5-18.2$ & $24.2-27.3$ & $20.8-29$ & \\
\hline Respiratory distress & $4.8-5.5$ & $3.2-4.8$ & $6.5-12.5$ & \\
\hline Perinatal death & $0.1-1.7$ & 0.5 & $0.1-3.1$ & \\
\hline
\end{tabular}

recommended for postpartum hypertension, with demonstrated safety in lactation in small cohorts, and pilot data showing improved diastolic function and left ventricular modelling compared with placebo after pre-term pre-eclampsia. ${ }^{16,17}$

Where severe hypertension is caused by pre-eclampsia, it confers a sevenfold chance of haemorrhagic stroke compared with severe hypertension in the absence of pre-eclampsia. In contrast, chronic hypertension has not been found to increase the risk of pregnancy-associated stroke. ${ }^{18}$ This difference is attributed to the disruption of cerebral autoregulation in pre-eclampsia, which leads to increased vulnerability to cerebrovascular injury, as well the progressive nature of endothelial dysfunction in pre-eclampsia. For this reason, in severe hypertension due to pre-eclampsia, the aim is to control blood pressure to $160 / 110 \mathrm{mmHg}$ within hours, followed by a target blood pressure of $110-140 / 70-85 \mathrm{mmHg}$. ${ }^{4,14}$ There are no data to guide the rate at which systolic blood pressures of $200 \mathrm{mmHg}$ or more should be corrected in pre-eclampsia. Consensus practice in non-pregnant hypertensive emergencies is to reduce systolic blood pressure by no more than $25 \%$ in the first hour, aiming for a systolic blood pressure below $160 \mathrm{mmHg}$ over the next 2-6 hours provided the patient remains stable. Intravenous labetalol can be used for precise, rapid titration and control. Intravenous hydralazine is also safe to use in pregnancy where labetalol is contraindicated or ineffective, with care to avoid rapid blood pressure changes and hypotension $(<110 / 70 \mathrm{mmHg}$ ). If a delay in intravenous treatment is anticipated due to the need for admission and high-level monitoring, then oral labetalol $(200 \mathrm{mg})$ or modified-release nifedipine $(10-20 \mathrm{mg})$ can be given, with doses repeated hourly. In the UK, modified-release preparations of nifedipine are used due to the risks of hypotension with immediate-release and sublingual preparations. The treatment of severe hypertension is detailed in Table 3 .

Additional aspects of care for women with pre-eclampsia and severe hypertension include intravenous magnesium sulphate for seizure prophylaxis, careful fluid balance with restriction of fluid to reduce the risk of pulmonary oedema, and assessment of fetal wellbeing. An inability to control maternal blood pressure may be an indication for preterm delivery, which remains the only cure for pre-eclampsia.

\section{Postpartum}

There is a postpartum rise in blood pressure, peaking on day 3-6 after delivery in both normotensive women and those with hypertension during pregnancy. Blood pressure and preeclampsia surveillance should therefore be continued in the first week postpartum. About one in five women with hypertension in pregnancy will have persistent chronic hypertension postpartum. A longer duration of antihypertensive treatment in pregnancy, higher maximum systolic and diastolic blood pressures, and preterm pre-eclampsia are all risk factors for sustained hypertension. ${ }^{19}$ Both chronic hypertension and pre-eclampsia are risk factors for cardiovascular disease, cerebrovascular disease and chronic kidney disease later in life, with endothelial dysfunction, angiogenic imbalance and chronic inflammatory changes hypothesised as potential pathophysiological mechanisms. ${ }^{20,21}$ 
In the absence of long-term prospective intervention studies, counselling of women following hypertensive disorders in pregnancy is advocated, with management of modifiable risk factors.

\section{Conclusion}

Severe hypertension in pregnancy has a consensus definition: a sustained systolic blood pressure of $160 \mathrm{mmHg}$ or above or diastolic blood pressure of $110 \mathrm{mmHg}$ or above. The most common cause of severe hypertension in pregnancy is preeclampsia, which confers an increased risk of haemorrhagic stroke. Severe hypertension is associated with adverse outcomes including abnormal liver function, preterm delivery and growth restriction, even in the absence of proteinuria. In contrast, severe hypertension before 20 weeks' gestation is rare and usually due to chronic hypertension; assessment for target organ damage and exclusion of secondary hypertension are warranted. Treatment of hypertension in pregnancy is determined by licensing, availability and clinician experience, with no high-level evidence to guide prescribing. Labetalol, modified-release nifedipine and methyldopa are widely used in pregnancy. Labetalol can be given orally and intravenously when urgent control of blood pressure is required in pre-eclampsia. Use of amlodipine, doxazosin and prazosin in pregnancy is described, although there are limited published safety data. Severe hypertension is a risk factor for sustained hypertension after pregnancy and all hypertension in pregnancy is associated with increased vascular risk later in life.

\section{References}

1 Green LJ, Mackillop LH, Salvi D et al. Gestation-specific vital sign reference ranges in pregnancy. Obstet Gynecol 2020;135:653-64.

2 Martin JN, Thigpen BD, Moore RC et al. Stroke and severe preeclampsia and eclampsia: a paradigm shift focusing on systolic blood pressure. Obstet Gynecol 2005;105:246-54.

3 Lewis G (ed). Saving mothers' lives: reviewing maternal deaths to make motherhood safer-2003-2005. Confidential Enquiry into Maternal and Child Health, 2007. www.publichealth.hscni.net/ publications/saving-mothers-lives-2003-2005 [Accessed 28 July 2021].

4 Brown MA, Magee LA, Kenny LC et al. International Society for the Study of Hypertension in Pregnancy (ISSHP). Hypertensive disorders of pregnancy: ISSHP classification, diagnosis, and management recommendations for international practice. Hypertension 2018;72:24-43.

5 Wiles K, Brown M. Renal physiology and complications in normal pregnancy. In Comprehensive clinical nephrology, 7th edn. Elsevier, 2021: in press.
6 Wiles K, Bramham K, Seed PT et al. Serum creatinine in pregnancy: a systematic review. Kidney Int Rep 2019:4:408-19.

7 Webster K, Fishburn S, Maresh M et al. Diagnosis and management of hypertension in pregnancy: summary of updated NICE guidance. BMJ 2019;366:15119.

8 Hauth JC, Ewell MG, Levine RJ et al. Pregnancy outcomes in healthy nulliparas who developed hypertension. Calcium for Preeclampsia Prevention Study Group. Obstet Gynecol 2000;95:24-8.

9 Buchbinder A, Sibai BM, Caritis $S$ et al. Adverse perinatal outcomes are significantly higher in severe gestational hypertension than in mild preeclampsia. Am J Obstet Gynecol 2002;186:66-71.

10 Magee LA, von Dadelszen P, Singer ] et al. The CHIPS Randomized Controlled Trial (Control of Hypertension in Pregnancy Study): Is severe hypertension just an elevated blood pressure? Hypertension 2016;68:1153-9.

11 Fishel Bartal M, Lindheimer MD, Sibai BM. Proteinuria during pregnancy: definition, pathophysiology, methodology, and clinical significance. Am J Obstet Gynecol 2020;S0002-9378(20)30989-3 [Epub ahead of print].

12 Magee LA, von Dadelszen P, Rey E et al. Less-tight versus tight control of hypertension in pregnancy. N Engl J Med 2015;372:407-17.

13 Abalos E, Duley L, Steyn DW, Gialdini C. Antihypertensive drug therapy for mild to moderate hypertension during pregnancy. Cochrane Database Syst Rev 2018;10:CD002252.

14 National Institute for Health and Care Excellence. Hypertension in pregnancy: diagnosis and management: NICE guideline [NG133]. NICE, 2019. www.nice.org.uk/guidance/ng133[Accessed 28 ]uly 2021].

15 Wiles K, Chappell L, Clark K et al. Clinical practice guideline on pregnancy and renal disease. BMC Nephrol 2019;20:401.

16 Redman CW, Kelly JG, Cooper WD. The excretion of enalapril and enalaprilat in human breast milk. Eur J Clin Pharmacol 1990;38:99.

17 Ormesher L, Higson S, Luckie M et al. Postnatal enalapril to improve cardiovascular function following preterm preeclampsia (PICk-UP): a randomized double-blind placebo-controlled feasibility trial. Hypertension 2020;76:1828-37.

18 Liu S, Chan W-S, Ray JG, Kramer MS, Joseph KS. Stroke and cerebrovascular disease in pregnancy: incidence, temporal trends, and risk factors. Stroke 2019;50:13-20.

19 Bramham K, Nelson-Piercy C, Brown MJ, Chappell LC. Postpartum management of hypertension. BMJ 2013;346:f894.

20 Thilaganathan B, Kalafat E. Cardiovascular system in preeclampsia and beyond. Hypertension 2019;73:522-31.

21 Kattah AG, Scantlebury DC, Agarwal S et al. Preeclampsia and ESRD: the role of shared risk factors. Am J Kidney Dis 2017;69: 498-505.

Address for correspondence: Dr Kate Wiles, The Royal London Hospital, Whitechapel Road, London E1 1FR, UK.

Email: kate.wiles@nhs.net

Twitter: @DrKateWiles 